\title{
Alkali Lignin from Rice [Oryza sativat.] Husk as Adsorbent for Aqueous Methyl Orange and Bromothymol Blue: Analysis of the Adsorption Kinetics and Mechanism
}

\author{
Marjorie Pearl C. Linde and Kevinilo P. Marquez ${ }^{*}$ \\ Institute of Chemistry, University of the Philippines Los Baños, Brgy. Batong Malake, Los Baños, Laguna 4031 \\ *Author to whom correspondence should be addressed; email: kgperez3@up.edu.ph
}

\begin{abstract}
In this study, lignin was isolated from rice (Oryza sativa L.) husk using alkaline extraction method and was used as an adsorbent for aqueous solutions of methyl orange (MO) and bromothymol blue (BTB). The equilibrium removal rate of MO was found to be at $61.4 \%$, with experimental equilibrium adsorbate uptake, $\mathrm{q}_{\mathrm{e}}$, of $1.23 \mathrm{mg} \cdot \mathrm{g}^{-1}$, achieved at 150 minutes contact time. For BTB, the equilibrium removal rate was found to be at $78.3 \%$, with an experimental $\mathrm{q}_{\mathrm{e}}$ of $1.57 \mathrm{mg} \cdot \mathrm{g}-1$, achieved at 150 minutes contact time. Pseudo-first order (PFO) and pseudo-second order (PSO) kinetic models were then used to investigate the kinetics of the adsorption process. Both MO and BTB on lignin were found to follow a PSO kinetic model, with rates of $6.84 \times 10^{-3} \mathrm{~g} \cdot \mathrm{mg}^{-1} \cdot \mathrm{min}^{-1}$ and $0.69 \mathrm{~g} \cdot \mathrm{mg}^{-1} \cdot \mathrm{min}^{-1}$, respectively. Langmuir, Freundlich, Dubinin-Radushkevich (DR), BrunauerEmmett-Teller (BET), Flory Huggins (FH), and Temkin adsorption isotherm models were then used to determine the appropriate equilibrium adsorption model for both substrates. Based on the calculations performed, the Temkin model best described the adsorptive removal of both MO and BTB. Based on the Temkin model, the adsorption processes of both MO and BTB were found to occur spontaneously, with equilibrium rate constants of $0.083 \mathrm{~L} \cdot \mathrm{mg}^{-1}$ and $0.012 \mathrm{~L} \cdot \mathrm{mg}^{-1}$, respectively.
\end{abstract}

Keywords: adsorption; adsorption isotherms; adsorption kinetics; lignin; bromothymol blue, methyl orange

\section{INTRODUCTION}

The discharge of various toxic chemicals from industrialization and urbanization leading to water pollution is a global concern nowadays. Among the different hazardous chemicals, the presence of toxic dyes in wastewaters from the effluents of textile, rubber, paper, leather, plastics, cosmetics, and printing industries causes severe damage to the environment even at low concentrations. Because dyes are highly colored substances, they affect the visibility and recalcitrance and generate several problems for ecosystem wastewater such as reduced sunlight 
penetration, resistance to photochemical and biological attack, and toxic or even mutagenic and carcinogenic degradation products. Therefore, removal of these dye pollutants is necessary for both health and environmental considerations (Subbaiah and Kim, 2016; Agarwal et al., 2016).

Conventional wastewater treatment methods such as biosorption, photodegradation, coagulation, electrochemical oxidation, ozonation, reverse osmosis, adsorption (Agarwal et al., Efficient, 2016), membrane separation process, electrochemical, aerobic and anaerobic microbial degradation had been used for the removal of dyes and pigments from aqueous solutions. However, most of these methods are limited by expensive procedure and generation of huge amounts of toxic wastes, which make them less efficient processes (Aliabadi et al., 2018). Compared to other methods, removal of dyes via adsorption is one of the most competitive methods due to its high removal efficiency, economic feasibility, and simplicity in design and operation (Gong et al., 2013).

In the recent years, increased interest is focused on lignin as an adsorbent alternative to other wastewater treatments. Lignin, the second most abundant and the most complex polymer in nature (Agarwal et al., 2018), is known to exhibit adsorption properties and has been used for the efficient removal of heavy metals and organic contaminants such as dyes, bile acid, surfactants, pesticides, phenols, and polycyclic aromatic hydrocarbons from aquatic environments (Han et al., 2012). Specifically, some adsorbents prepared from lignin have attracted considerable interest. Different studies have been made and these studies indicate that lignin-based materials can be used as adsorbents for dye removal. Mahmoudi et al. (2012) prepared an activated carbon from lignin by $\mathrm{ZnCl}_{2}$ chemical activation. The adsorption experiments indicate that the activated carbon from lignin has a good adsorption capacity for methyl orange ions from aqueous solutions. Liu and Huang (2006) prepared a spherical sulfonic lignin adsorbent from sodium lignosulfonate crosslinked by formaldehyde in an aqueous solution suspended in transformer oil, which showed favorable adsorption of cationic red GTL, cationic turquoise GB, and cationic yellow X-5GL. Wang et al. (2018) examined the Congo red and Eriochrome blue black R adsorption by a carbon composite lignin-based adsorbent. However, the adsorption behavior of the precursor of these materials has rarely been reported.

In this study, adsorptive removal of aqueous methyl orange (MO) and bromothymol blue (BTB) by alkali lignin isolated from rice husk was investigated. Analysis using kinetic models including pseudo-first order (PFO) and pseudo-second order (PSO), and adsorption isotherm models such as Langmuir, Freundlich, Dubinin-Radushkevich (DR), Brunauer-Emmett-Teller (BET), FloryHuggins (FH), and Temkin, were employed to evaluate the sorption process and to provide better understanding about the adsorption characteristic and efficiency.

\section{METHODS}

Materials and Equipment. Rice husks were obtained from a rice mill in Bay, Laguna. Sodium hydroxide pellets were purchased from Macron Fine Chemicals ${ }^{\mathrm{TM}}$. Concentrated sulfuric acid was purchased from Duksan Pure Chemicals Co. Methyl orange and bromothymol blue were purchased from Techno Pharmchem, India. All chemical reagents were used as received and without further purification. Characterization of lignin was performed using Shimadzu IRSpirit. UV-Vis analyses for the adsorption experiments were performed using a Shimadzu UV-1280.

Sample Preparation. Rice husks were washed with distilled water and then sun-dried to remove adherent moisture. The dried samples were then crushed using a Wiley mill and then sieved through a mesh size of 40 ( $0.425 \mathrm{~mm}$ opening) using a mechanical sieve shaker.

Alkaline Extraction of Lignin. The method described by Tumolva et al. (2016) with modifications was used for the alkaline extraction of lignin. Optimum operating conditions were based on the 
study conducted by Conti (2019). Fifty grams of milled rice husks were refluxed in $1000 \mathrm{~mL}$ of 4.0 $\mathrm{M} \mathrm{NaOH}$ solution for 90 minutes. The mixture was allowed to cool down before proceeding to suction filtration. Precipitation of lignin was carried out by adding concentrated $\mathrm{H}_{2} \mathrm{SO}_{4}$ to the filtrate until pH 2 is reached. The mixture was then heated at $80^{\circ} \mathrm{C}$ for 40 minutes, and the alkali lignin was recovered through filtration afterwards. The residue was air-dried under fume hood and was pulverized using mortar and pestle. Lignin percent (\%) yield was determined by using the equation:

$$
\text { Lignin percent (\%) yield }=\frac{\text { mass of the residue,g }}{\text { mass of the sample,g }} \times 100 \%
$$

Characterization of Alkali Lignin. Lignin isolated from rice husks was characterized using UVVis and Fourier Transform Infrared (FT-IR) spectroscopy. The spectrum of the extracted alkali lignin was recorded from 4000 to $400 \mathrm{~cm}^{-1}$ at a resolution of $4 \mathrm{~cm}^{-1}$.

Methyl Orange and Bromothymol Blue Adsorption. A modified procedure described by Nair et al. (2014) was adapted for the adsorption of MO and BTB on lignin. Adsorption studies were performed by contacting $250 \mathrm{mg}$ of alkali lignin with $50 \mathrm{~mL}$ of $10 \mathrm{mg} \cdot \mathrm{L}^{-1}$ dye solution from 15 to 240 minutes (at 15-minute interval) at room temperature. After stirring, the suspensions were filtered and the filtrates were adjusted to $\mathrm{pH} 10$ by adding $0.1 \mathrm{M} \mathrm{NaOH}$ solution. Using a UV-Vis spectrophotometer, the absorbance of the alkaline filtrates of MO and BTB were recorded at 464 $\mathrm{nm}$ and $616 \mathrm{~nm}$, respectively. The final concentrations of MO and BTB in the filtrates were determined based on a standard curve. The amount of dye adsorbed on lignin, $q(\mathrm{mg} / \mathrm{g})$, and the adsorption percentage $(\% \mathrm{R})$ were calculated using the equations (Nsami and Mbadcam, 2013):

$$
\begin{gathered}
q=\frac{\left(C_{i}-C_{f}\right) V}{m} \\
\% R=\frac{\left(C_{i}-C_{f}\right)}{C_{i}} \times 100 \%
\end{gathered}
$$

Adsorption Kinetic Studies. The kinetic data of MO and BTB adsorption were treated with linearized PFO and PSO models given by equations 4 and 5, respectively:

$$
\begin{gathered}
\ln \left(q_{e}-q_{t}\right)=\ln q_{e}-k_{1} t \\
\frac{t}{q_{t}}=\frac{1}{k_{2} q_{e}^{2}}+\frac{1}{q_{e}} t
\end{gathered}
$$

The coefficient of determination, $\mathrm{R}^{2}$, and the standard deviation (SD), $\Delta \mathrm{q}$, of each model were calculated for both dyes. The one with $\mathrm{R}^{2}$ closer to unity, and lower $\Delta \mathrm{q}$ value is considered the appropriate model that fits the experimental data (Moussout et al., 2018).

$$
\Delta q(\%)=\sqrt{\frac{\sum\left[\left(q_{t, \text { exp }}-q_{t, c a l}\right) / q_{t, \exp }\right]^{2}}{n-1}} \times 100 \%
$$

Adsorption Isotherm Modelling. The adsorption equilibrium of both MO and BTB on lignin were analyzed using Langmuir, Freundlich, Dubinin-Radushkevich, Brunauer-Emmett-Teller, FloryHuggins, and Temkin isotherms models.

Langmuir

Freundlich

Dubinin-Radushkevic (DR)

Breuner-Emett-Teller (BET)

Flory-Huggins (FH)

Temkin

$$
\begin{gathered}
\frac{C_{e}}{q_{e}}=\frac{1}{K_{L} q_{\max }}+\frac{C_{e}}{q_{\max }} \\
\log \left(q_{e}\right)=\log \left(K_{F}\right)+\frac{1}{n} \log \left(C_{e}\right) \\
\ln \left(q_{e}\right)=\ln \left(q_{s}\right)-K_{D R} \varepsilon^{2} \\
\frac{C_{e}}{q_{e}\left(C_{S}-C_{e}\right)}=\frac{1}{q_{s} C_{B E T}}+\frac{C_{B E T}-1}{q_{s} C_{B E T}} \cdot \frac{C_{e}}{C_{s}} \\
\ln \left(\frac{\theta}{C_{o}}\right)=\ln \left(K_{F H}\right)+\mathrm{n} \ln (1-\theta) \\
q_{e}=B \ln \left(K_{T}\right)+\frac{R T}{b} \ln \left(C_{e}\right)
\end{gathered}
$$


The summary of the definitions of each term in equations 7-12 is shown in Table 1.

Table 1. Table of Nomenclature.

\begin{tabular}{|c|c|}
\hline Symbol & Meaning \\
\hline$q_{\mathrm{t}}$ & adsorption capacity at time $\mathrm{t}\left(\mathrm{mg} \cdot \mathrm{g}^{-1}\right)$ \\
\hline$q_{\mathrm{e}}$ & adsorption capacity at equilibrium $\left(\mathrm{mg} \cdot \mathrm{g}^{-1}\right)$ \\
\hline$q_{\mathrm{t}, \mathrm{exp}}$ & experimental adsorption capacity at time $\mathrm{t}\left(\mathrm{mg} \cdot \mathrm{g}^{-1}\right)$ \\
\hline$q_{\mathrm{t}, \mathrm{cal}}$ & calculated adsorption capacity at time $\mathrm{t}\left(\mathrm{mg} \cdot \mathrm{g}^{-1}\right)$ \\
\hline$q_{\mathrm{e}, \mathrm{exp}}$ & experimental adsorption capacity at equilibrium $\left(\mathrm{mg} \cdot \mathrm{g}^{-1}\right)$ \\
\hline$q_{\mathrm{e}, \mathrm{cal}}$ & calculated adsorption capacity at equilibrium $\left(\mathrm{mg}^{-\mathrm{g}^{-1}}\right)$ \\
\hline$q_{\max }$ & maximum adsorption capacity (mg·g-1) \\
\hline$q_{\mathrm{s}}$ & theoretical isotherm saturation capacity $\left(\mathrm{mg} \cdot \mathrm{g}^{-1}\right)$ \\
\hline$C_{\mathrm{o}}$ & initial concentration of adsorbate $\left(\mathrm{mg} \cdot \mathrm{L}^{-1}\right)$ \\
\hline$C_{\mathrm{f}}$ & final concentration of adsorbate $\left(\mathrm{mg} \cdot \mathrm{L}^{-1}\right)$ \\
\hline$C_{\mathrm{e}}$ & concentration of adsorbate at equilibrium $\left(\mathrm{mg} \cdot \mathrm{L}^{-1}\right)$ \\
\hline$C_{\mathrm{s}}$ & adsorbate monolayer saturation concentration $\left(\mathrm{mg} \cdot \mathrm{L}^{-1}\right)$ \\
\hline$C_{\mathrm{BET}}$ & BET adsorption isotherm constant $\left(\mathrm{L} \cdot \mathrm{mg}^{-1}\right)$ \\
\hline$k_{1}$ & Pseudo-first order kinetic model rate constant $\left(\mathrm{min}^{-1}\right)$ \\
\hline$k_{2}$ & Pseudo-second order kinetic model rate constant $\left(\mathrm{g} \cdot \mathrm{mg}^{-1} \cdot \mathrm{min}^{-1}\right)$ \\
\hline$K_{\mathrm{L}}$ & Langmuir isotherm constant $\left({\left.\mathrm{L} \cdot \mathrm{mg}^{-1}\right)}^{-10}\right.$ \\
\hline$K_{\mathrm{F}}$ & Freundlich isotherm constant $\left(\mathrm{L} \cdot \mathrm{mg}^{-1}\right)$ \\
\hline$K_{\mathrm{DR}}$ & Dubinin-Radushkevich isotherm constant $\left(\mathrm{mol}^{2} \cdot \mathrm{J}^{-2}\right)$ \\
\hline$K_{\mathrm{FH}}$ & Flory Huggins isotherm constant $\left(\mathrm{L} \cdot \mathrm{mg}^{-1}\right)$ \\
\hline$K_{\mathrm{T}}$ & Temkin isotherm constant $\left(\mathrm{L} \cdot \mathrm{mg}^{-1}\right)$ \\
\hline$T$ & adsorption contact time (min) \\
\hline$V$ & volume of the solution (L) \\
\hline$n$ (Freundlich) & adsorption favorability \\
\hline$n$ (Flory Huggins) & number of adsorbates occupying adsorption sites \\
\hline$n(\mathrm{SD}, \mathrm{SSE}, \mathrm{SAE}, \mathrm{ARE})$ & number of data points \\
\hline$\varepsilon$ & Polanyi potential $\left(\mathrm{J} \cdot \mathrm{mol}^{-1}\right)=\mathrm{RT} \ln \left[1+\left(1 / \mathrm{C}_{\mathrm{e}}\right)\right]$ \\
\hline$\theta$ & degree of surface coverage $=1-\left(\mathrm{C}_{\mathrm{e}} / \mathrm{C}_{\mathrm{o}}\right)$ \\
\hline$b$ & constant related to the heat of sorption $\left(\mathrm{J} \cdot \mathrm{mol}^{-1}\right)$ \\
\hline$B$ & Temkin constant equal to RT/b \\
\hline$R$ & universal gas constant $\left(8.314 \mathrm{~J} \cdot \mathrm{mol}^{-1} \cdot \mathrm{K}^{-1}\right)$ \\
\hline$T$ & absolute temperature $(\mathrm{K})$ \\
\hline
\end{tabular}

The most suitable isotherm model for representing the experimental data was determined through analysis of the coefficient of determination, $\mathrm{R}^{2}$, and through three error functions - sum of squared errors (SSE), sum of absolute errors (SAE), and average relative error (ARE), which are given by Equations 13, 14, and 15, respectively (Piccin et al., 2011).

$$
\begin{gathered}
S S E=\sum_{i=1}^{n}\left(q_{t, \text { cal }}-q_{t, \exp }\right)_{i}^{2} \\
S A E=\sum_{i=1}^{n}\left|q_{t, \text { cal }}-q_{t, \exp }\right|_{i} \\
A R E=\frac{\sum_{i=1}^{n}\left|\frac{q_{t, \text { cal }}-q_{t, \exp }}{q_{t, \text { exp }}}\right|_{i}}{n} \times 100 \%
\end{gathered}
$$




\section{RESULTS AND DISCUSSION}

Alkaline Extraction of Lignin. A good adsorbent should have a porous structure resulting to higher surface area. For this reason, different synthesis techniques and post-treatment approaches have been made by researchers to improve the adsorption properties of adsorbents. Among these methods, alkali treatment appears to be an effective route to improve the surface area and pore volume (Ma et al., 2012). Thus, in this study, alkaline pre-treatment method was employed for the extraction of lignin from rice husks.

A physical pre-treatment was first done by milling the rice husks to fragment the lignocellulosic chain into smaller parts. This would consequently increase the surface area of the biomass and expose all lignocellulosic structures to reagents in further treatment steps. The sample was then subjected to alkaline pre-treatment with $4.0 \mathrm{M} \mathrm{NaOH}$ to enable extensive delignification, which is expected to cause swelling, which then results in an increase in the surface area, decrease in the polymerization and crystallinity ratios, and separation of the structural bonds between lignocellulosic components (Kucharska et al., 2018). The mixture was filtered afterwards, and lignin was precipitated from the filtrate by adding concentrated $\mathrm{H}_{2} \mathrm{SO}_{4}$. After heating and filtration, $8.47 \mathrm{~g}$ of brown alkali lignin was obtained. The method produced a yield of $16.94 \%$.

Characterization of Lignin. The chemical information regarding the typical functional groups of the isolated lignin was analyzed using FT-IR spectroscopy. The FT-IR spectrum of the isolated lignin is shown in Figure 1.

The peak observed at $3431.25 \mathrm{~cm}^{-1}$ was due to the stretching vibrations of alcoholic and phenolic hydroxyl groups. The large absorption area implied that the isolated alkali lignin was abundant in $\mathrm{O}-\mathrm{H}$ group. The stretching signal at $1627.10 \mathrm{~cm}^{-1}$ can be assigned to the presence of $\mathrm{C}=\mathrm{C}$ in conjugated alkenes. The peak at $1508.31 \mathrm{~cm}^{-1}$ is due to the aromatic ring vibration, which is a characteristic absorption peak of lignin (Hua et al., 2016). The peak at $1160.25 \mathrm{~cm}^{-1}$ can be assigned to the $\mathrm{C}-\mathrm{O}$ stretch in tertiary alcohol while the signal at $1042.13 \mathrm{~cm}^{-1}$ can be attributed to aromatic $\mathrm{C}-\mathrm{H}$ in-plane deformation for guaiacyl types. Lastly, the peaks at 860.36 and 787.5 $\mathrm{cm}^{-1}$ are due to aromatic C-H out of plane bending (Sigma-Aldrich, 2020).

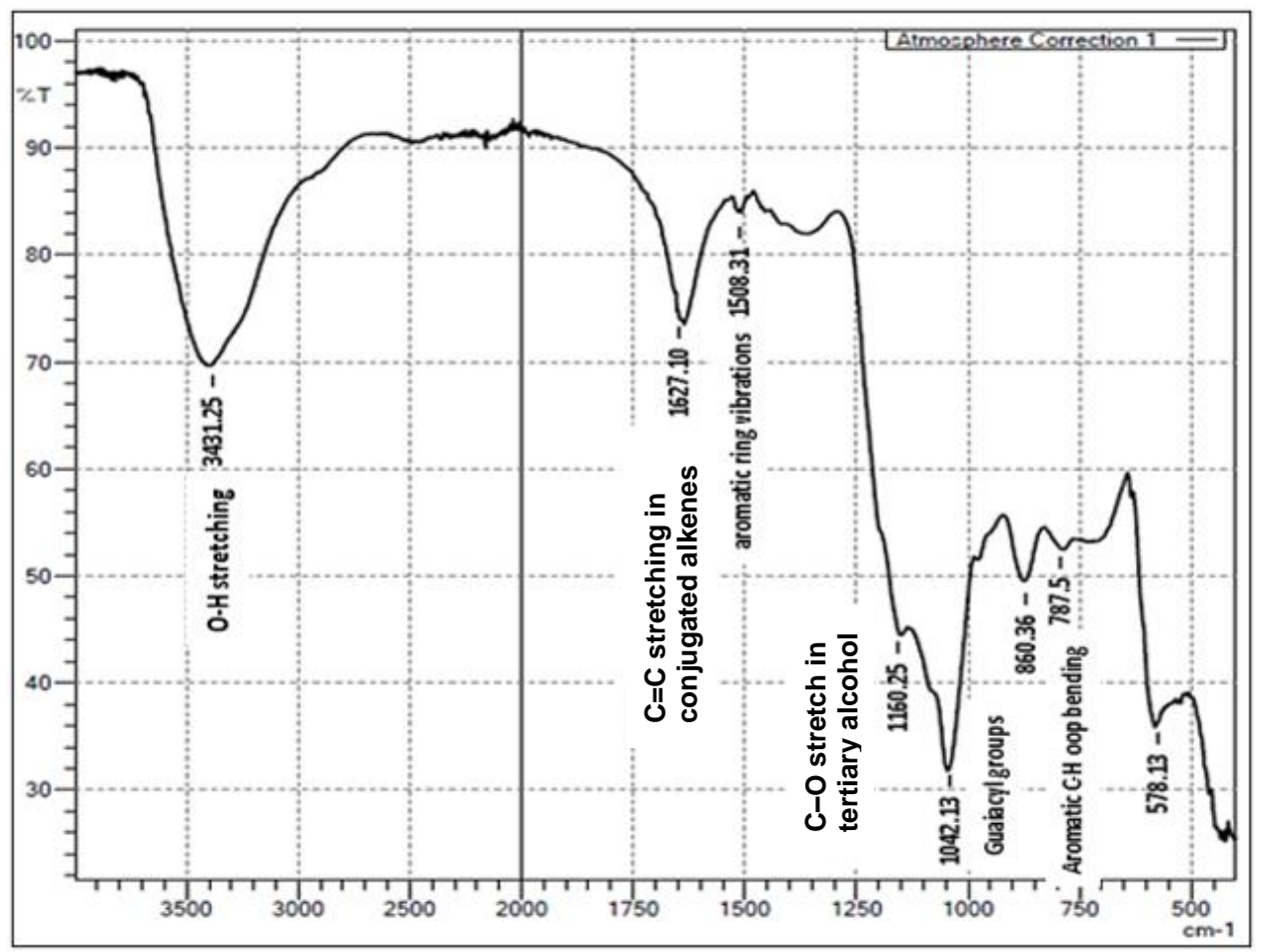

Figure 1. FT-IR Spectrum of the Isolated Alkali Lignin 
Methyl Orange and Bromothymol Blue Adsorption. The isolated alkali lignin was used to study the adsorption of $\mathrm{MO}$ and BTB. A plot of the adsorbate uptake against time was made to show the effect of contact time on the adsorption process are shown in Figures 2 and 3.

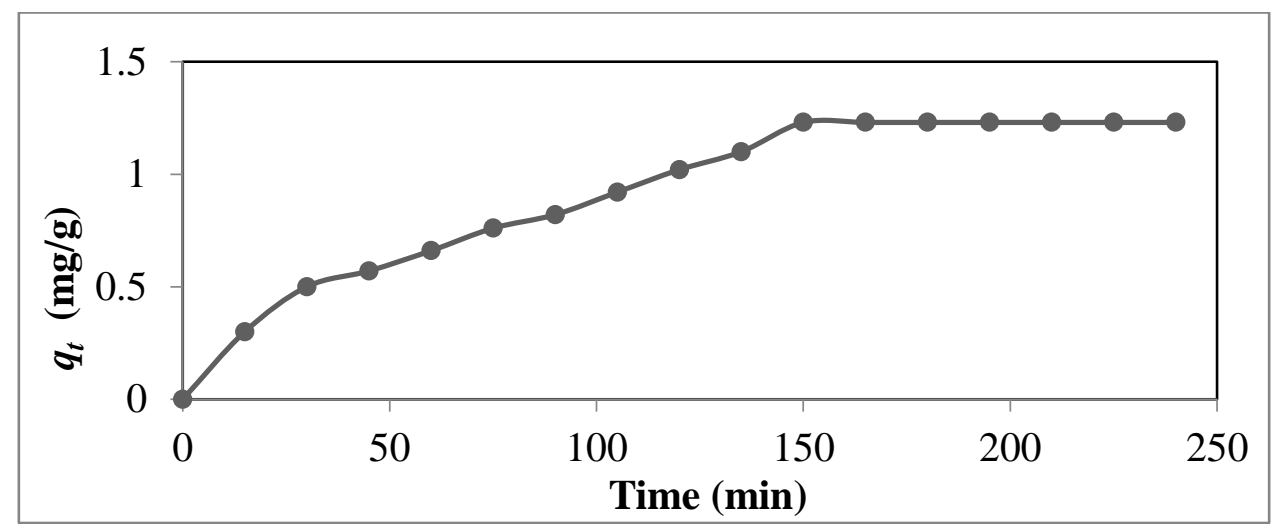

Figure 2. Effect of Contact Time on the Adsorption of MO on Lignin

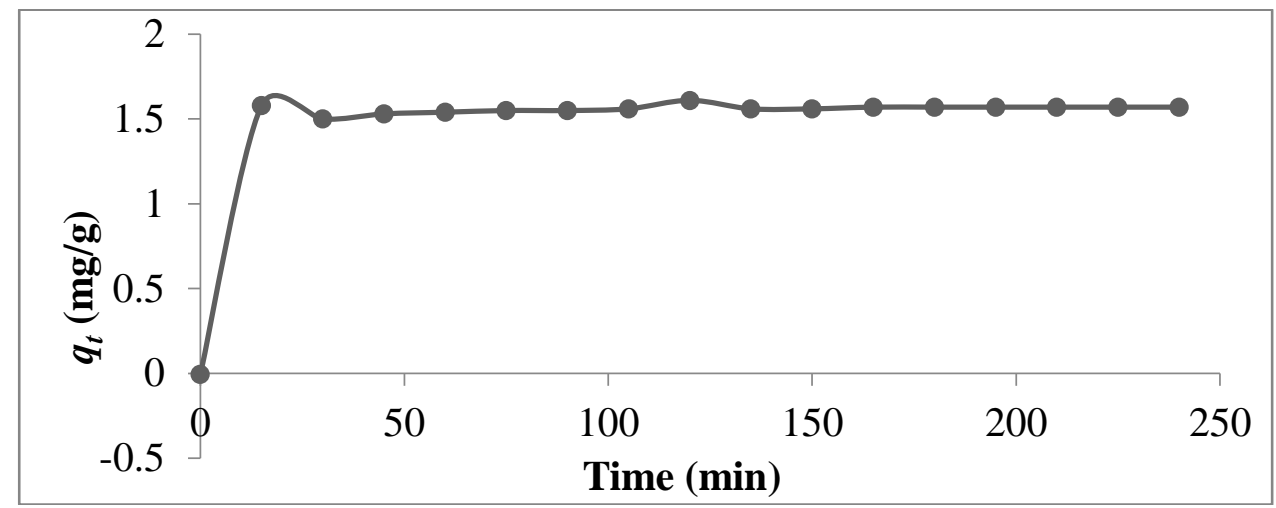

Figure 3. Effect of Contact Time on the Adsorption of BTB on Lignin

It can be observed in Figure 2 that the experimental points can be divided into two regions. In the first region, the uptake of MO increased with time; however, after contact time $t=150$ minutes (second region), the $\mathrm{q}_{\mathrm{t}}$ values became constant. This difference in the rate of adsorption can be related to the number and the availability of the adsorption sites over time (Moussout et al., 2018). Equilibrium was achieved at 150 minutes with a removal rate of $61.4 \%$, wherein the $\mathrm{q}_{\mathrm{e}, \exp }$ is $1.23 \mathrm{mg} \cdot \mathrm{g}^{-1}$. On the other hand, Figure 3 shows that BTB readily adsorbed onto lignin. The equilibrium removal rate was found to be at $78.3 \%$, with $\mathrm{q}_{\mathrm{e}, \exp }$ of $1.57 \mathrm{mg} \cdot \mathrm{g}-1$, achieved at 150 minutes contact time.

The type of extracted lignin may also have affected the removal rate of the substrates, mainly due to the differences in the amount of adsorption sites. In the study of Zhang et al., (2016) organosolv lignin extracted from rice straw showed a peak average equilibrium removal of $20 \mathrm{mg} \cdot \mathrm{g}^{-1}$ lignin at a pH range of 5 to 9, obtained after at least 120 minutes contact time. It can be observed in their findings that the removal rate only decreases by $33.3 \%$ from $\mathrm{pH} 5$ to 3 , while it is consistent from pH 5 to 9. This suggests that $\mathrm{pH}$, except for extreme cases, may have little effect in the adsorption characteristics of MO in lignin. Also, it can be concluded that organosolv lignin may have a greater number of adsorption sites compared to alkali lignin. However, aside from the Langmuir and Freundlich isotherms, other isotherm models could have been explored.

Adsorption Kinetic Studies. To study the evolution of the adsorption process over time, the kinetic data of MO and BTB adsorption were analyzed using linearized PFO and PSO models. A 
PFO reaction is a second order reaction by nature but has been altered by changing the concentration of one or the other reactant to make it a first order reaction. On the other hand, a PSO reaction is nearly second order but is modified by additional factors. The reaction has more than two molecularities but only two molecules are involved in the determining step which decides the order of reaction (Robati, 2013).

Kinetic analysis of the adsorption of MO on lignin shows that the PSO model has an $\mathrm{R}^{2}$ value of 0.9719 , which is closer to 1 , and a lower $\Delta \mathrm{q}$ of $6.91 \%$ compared to that of the PFO model, which gave an $\mathrm{R}^{2}$ value of 0.9432 and a $\Delta \mathrm{q}$ of $9.26 \%$, as shown in Table 2 . Therefore, the adsorption of MO on lignin follows a PSO rate equation with a calculated rate constant, $\mathrm{k}_{2}$ of $6.84 \times 10^{-3} \mathrm{~g} \cdot \mathrm{mg}-$ $1 \cdot \min ^{-1}$.

Table 2. Kinetic Analysis of the Adsorption of MO on Lignin.

\begin{tabular}{|l|r|r|}
\hline Parameter & Pseudo-First Order (PFO) & Pseudo-Second Order (PSO) \\
\hline Slope & -0.0149 & 0.5762 \\
\hline Intercept & 0.2559 & 48.5693 \\
\hline $\mathrm{R}^{2}$ & 0.9432 & 0.9719 \\
\hline Equilibrium Rate Constant & $\mathrm{k}_{1}=0.015 \mathrm{~min}^{-1}$ & $\mathrm{k}_{2}=6.84 \times 10^{-3} \mathrm{~g}^{-\mathrm{mg}^{-1} \cdot \mathrm{min}^{-1}}$ \\
\hline $\mathrm{q}_{\mathrm{e}, \exp }(\mathrm{mg} / \mathrm{g})$ & 1.23 & 1.23 \\
\hline $\mathrm{q} \mathrm{eq}, \mathrm{al}(\mathrm{mg} / \mathrm{g})$ & 1.29 & 1.74 \\
\hline$\Delta \mathrm{q}(\%)$ & 9.26 & 6.91 \\
\hline
\end{tabular}

Using the same basis for the validity of a kinetic model, analysis of the adsorption of BTB on lignin (Table 3) shows that it also conformed with the PSO model rather than the PFO, as confirmed by its $\mathrm{R}^{2}$ value of 0.9998 , almost equal to 1 , and lower $\Delta \mathrm{q}$ of $1.75 \%$. The calculated PSO rate of reaction is $0.69 \mathrm{~g} \cdot \mathrm{mg}^{-1} \cdot \mathrm{min}^{-1}$.

Table 3. Kinetic Analysis of the Adsorption of BTB on Lignin.

\begin{tabular}{|l|r|r|}
\hline Parameter & Pseudo-First Order (PSO) & Pseudo-Second Order (PFO) \\
\hline Slope & -0.0188 & 0.6338 \\
\hline Intercept & -2.3213 & 0.5786 \\
\hline $\mathrm{R}^{2}$ & 0.9144 & 0.9998 \\
\hline Equilibrium Rate Constant & $\mathrm{k}_{1}=0.019 \mathrm{~min}^{-1}$ & $\mathrm{k}_{2}=0.69 \mathrm{~g} \cdot \mathrm{mg}^{-1} \cdot \mathrm{min}^{-1}$ \\
\hline $\mathrm{q}_{\mathrm{e}, \exp }(\mathrm{mg} / \mathrm{g})$ & 1.57 & 1.57 \\
\hline $\mathrm{q}_{\mathrm{eq}, \mathrm{cal}}(\mathrm{mg} / \mathrm{g})$ & 0.10 & 1.58 \\
\hline$\Delta \mathrm{q}(\%)$ & 98.05 & 1.75 \\
\hline
\end{tabular}

For both adsorption processes, the PSO model assumes that adsorption rate is proportional to the available sites on the adsorbent, while the rate of reaction depends on the amount of solute on the surface of the adsorbent (Kajjumba et al., 2018). The positive rates of reaction of the adsorption of MO and BTB imply that both adsorption processes are favorable, which also explains the high removal rate of both dyes even at low contact time (Moussout et al., 2018). This could also be explained by the similarities between the structures of the dyes and the lignin adsorbent (Figure 4). Once adsorbed, the dye molecules could also act as adsorbent sites, which promotes further adsorption. 


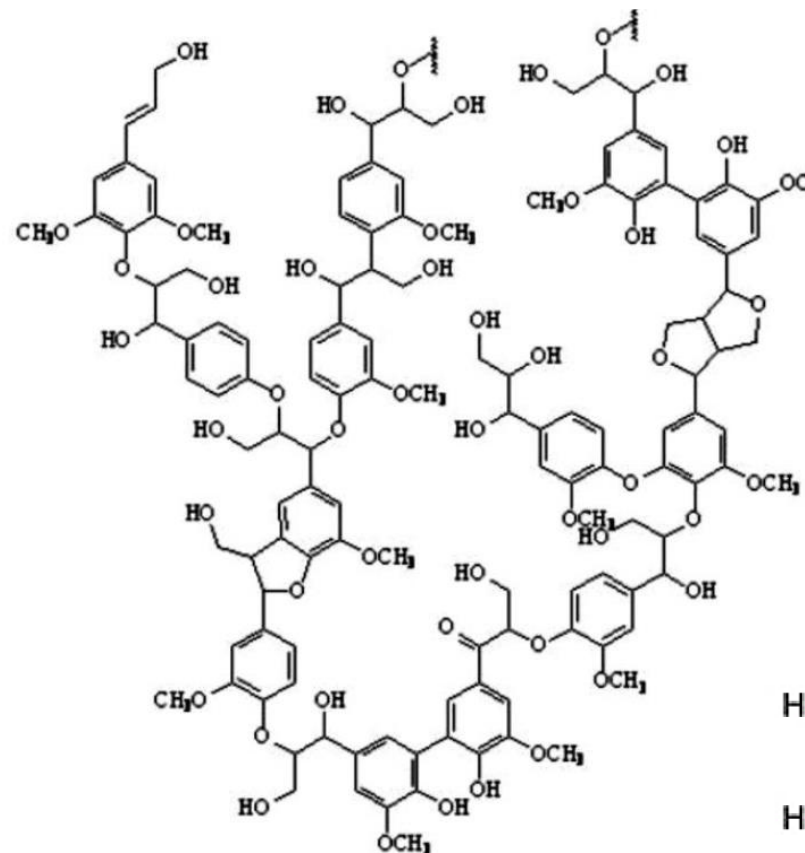

(a)<smiles></smiles>

(b)<smiles>CN(C)c1ccc(/N=N/c2ccc(S(=O)(=O)[O-])cc2)cc1</smiles>

(c)

Figure 4. Representative Structures of (a) Lignin (From Beduk, 2018), (b) Bromothymol Blue (From Agarwal et al., 2016), and (c) Methyl Orange (From Mahmoudi et al., 2011)

Adsorption Isotherm Modelling. An adsorption isotherm describes how the adsorbate will interact with the adsorbent and gives an idea of the adsorption capacity of the adsorbent. The data could also provide knowledge on the thermodynamics of the adsorption, such as the equilibrium constant, free energy, and enthalpy, among others. Thus, analysis of equilibrium adsorption data by fitting them to different isotherm models is a key step to find the suitable model (Bharathi and Ramesh, 2013).

The data obtained from the equilibrium adsorption analysis for MO and BTB using Langmuir, Freundlich, Dubinin-Radushkevich, Brunauer-Emmett-Teller, Flory-Huggins, and Temkin isotherms models are shown in Table 4.

Table 4. Isotherm Parameters for the Removal of MO and BTB by Lignin.

\begin{tabular}{|c|c|c|c|c|c|}
\hline \multirow{2}{*}{ Parameters } & \multicolumn{2}{|c|}{ Value } & \multirow{2}{*}{ Parameters } & \multicolumn{2}{|c|}{ Value } \\
\hline & MO & ВТВ & & Mo & BTB \\
\hline Langmuir & & & $F H$ & & \\
\hline $\mathrm{q}_{\max }\left(m g \cdot \mathrm{g}^{-1}\right)$ & 0.26 & 1.21 & $\mathrm{n}$ & -1.40 & -0.28 \\
\hline $\mathrm{K}_{\mathrm{L}}\left(\mathrm{L} \cdot \mathrm{mg}^{-1}\right)$ & -0.30 & -2.02 & $\mathrm{~K}_{\mathrm{FH}}\left(\mathrm{L} \cdot \mathrm{mg}^{-1}\right)$ & 0.017 & 0.051 \\
\hline $\mathrm{R}_{\mathrm{L}}$ & -0.50 & -0.05 & $\Delta \mathrm{G}^{\mathrm{o}}\left(\mathrm{kJ} \cdot \mathrm{mol}^{-1}\right)$ & -10.04 & -7.34 \\
\hline $\mathrm{R}^{2}$ & 0.8312 & 0.9983 & $\mathrm{R}^{2}$ & 0.9159 & 0.9966 \\
\hline Freundlich & & & $B E T$ & & \\
\hline $\mathrm{n}$ & -0.71 & -3.52 & $\mathrm{C}_{\mathrm{BET}}\left(\mathrm{L} \cdot \mathrm{mg}^{-1}\right)$ & 0.97 & 0.26 \\
\hline $\mathrm{K}_{\mathrm{F}}\left(\mathrm{L} \cdot \mathrm{mg}^{-1}\right)$ & 8.66 & 1.95 & $\mathrm{q}_{\mathrm{s}}(\mathrm{mg} \cdot \mathrm{g}-1)$ & -0.22 & -0.11 \\
\hline $\mathrm{R}^{2}$ & 0.9167 & 0.9805 & $\mathrm{R}^{2}$ & 0.0023 & 0.8217 \\
\hline$D R$ & & & Temkin & & \\
\hline $\mathrm{q}_{\mathrm{s}}\left(\mathrm{mg} \cdot \mathrm{g}^{-1}\right)$ & 0.38 & 1.32 & B & -1.10 & -0.44 \\
\hline $\mathrm{K}_{\mathrm{DR}}\left(\mathrm{mol}^{2} \cdot \mathrm{J}^{-2}\right)$ & $-3.82 \times 10^{-6}$ & $-1.97 \times 10^{-7}$ & $\mathrm{~b}\left(\mathrm{~J} \cdot \mathrm{mol}^{-1}\right)$ & -2240.28 & -5573.75 \\
\hline $\mathrm{E}\left(\mathrm{J} \cdot \mathrm{mol}^{-1}\right)$ & 33.68 & 43.20 & $\mathrm{~K}_{\mathrm{T}}\left(\mathrm{L} \cdot \mathrm{mg}^{-1}\right)$ & 0.083 & 0.013 \\
\hline $\mathrm{R}^{2}$ & 0.8180 & 0.9614 & $\mathrm{R}^{2}$ & 0.9903 & 0.9829 \\
\hline
\end{tabular}


Unlike the kinetic model-fitting method, selection of the most appropriate adsorption isotherm method is not limited to the comparison of the coefficients of variation $\left(\mathrm{R}^{2}\right)$ for each model. There are specific parameters in each model that should satisfy certain criteria before the model could be considered as a valid representation of the adsorption process. Comparison of the $\mathrm{R}^{2}$ values is usually the last step in the proper selection of the appropriate isotherm model.

The Langmuir isotherm is valid for monolayer adsorption onto a surface containing a finite number of adsorption sites. It assumes that (a) maximum adsorption is achieved when the surface reaches a saturation point, which means once a site is filled, no further sorption can take place at that site; (b) the energy of adsorption is constant and is distributed uniformly at the surface; and (c) there is no transmigration of adsorbate in the plane of the surface (Jain, 2006).

The essential characteristics of the Langmuir isotherm can be expressed by a dimensionless constant called the separation factor, $\mathrm{R}_{\mathrm{L}}$, which can also be used to check the favorability of the isotherm. The adosrption is said to be unfavorable when $R_{L}>1$, linear when $R_{L}=1$, favorable when $0<R_{L}<1$, and irreversible when $R_{L}=0$ (Ayawei et al., 2017).

$$
R_{L}=\frac{1}{1+K_{L} C_{o}}
$$

From the data presented, a negative $\mathrm{R}_{\mathrm{L}}$ value $(-0.50)$ was obtained for the adsorption of MO on lignin. This indicates that Langmuir isotherm model cannot be used to describe the adsorption equilibrium of MO, which is also supported by the low value of $R^{2}(0.8312)$ of the isotherm. Similarly, in the case of BTB, the negative $\mathrm{R}_{\mathrm{L}}$ value $(-0.05)$ despite having a coefficient of determination close to unity (0.9983) showed that Langmuir isotherm model is not followed for the adsorption of BTB on lignin.

The Freundlich adsorption model, on the other hand, is an empirical relationship that describes the sorption of solutes from a liquid to a solid surface of heterogeneous systems (Desta, 2013). The slope of the linear regression of the isotherm gives the constant $n$, which indicates the isotherm favorability. Adsorption is favorable when $\mathrm{n}<1$, linear when $\mathrm{n}=1$, and unfavorable when $\mathrm{n}>1$ (Theivarasu and Mylsamy, 2011). Using the Freundlich analysis, the calculated coefficients of determination for the adsorption of MO and BTB were 0.9167 and 0.9805 , respectively. The obtained $\mathrm{R}^{2}$ values suggest that the Freundlich model could fit both adsorption processes consequently proving that the adsorption sites are not identical and that the surface of lignin is heterogeneous. The calculated values for adsorption favorability, n, was -0.71 for MO and -3.52 for BTB, which imply that the adsorption of both dyes on lignin are favorable. The calculated sorption capacity constants were $8.66 \mathrm{~L} \cdot \mathrm{mg}^{-1}$ for $\mathrm{MO}$ and $1.95 \mathrm{~L} \cdot \mathrm{mg}^{-1}$ for BTB.

The DR isotherm is a semi empirical model, which follows a pore filling mechanism rather than layer-by layer surface coverage. It is used to describe adsorption on microporous carbons (Zhou, 2020). The Polanyi potential, $\varepsilon$, is related to mean adsorption energy, $\mathrm{E}\left(\mathrm{kJ} \cdot \mathrm{mol}^{-1}\right)$, which provides information about the adsorption process. When $\mathrm{E}<8 \mathrm{~kJ} \cdot \mathrm{mol}^{-1}$, physisorption dominates the sorption mechanism. When $\mathrm{E}>16 \mathrm{~kJ} \cdot \mathrm{mol}^{-1}$, particle diffusion is the dominant mechanism. When $8 \mathrm{~kJ} \cdot \mathrm{mol}^{-1}<\mathrm{E}<16 \mathrm{~kJ} \cdot \mathrm{mol}^{-1}$, a chemisorptive mechanism is followed (Hu and Zhang, 2019). The mean adsorption energy is given by the equation:

$$
E=\sqrt{2 \varepsilon}
$$

The $\mathrm{R}^{2}$ for the adsorption of MO using DR analysis is 0.8180 . Since the linear correlation is low, assumptions of the DR model does not hold true to the adsorption equilibrium of MO. On the other hand, the $\mathrm{R}^{2}$ for the adsorption of BTB is 0.9614 , which could indicate that the adsorption follows a pore-filling mechanism on a heterogeneous surface. However, the negative value of the isotherm constant, $\mathrm{K}_{\mathrm{DR}}\left(-1.97 \times 10^{-7} \mathrm{~mol}^{2} \cdot \mathrm{J}^{-2}\right)$, and the positive value of the calculated adsorption energy, $\mathrm{E}$ 
(43.20 $\mathrm{J} \cdot \mathrm{mol}^{-1}$ ) indicate that the adsorption of BTB on lignin is endothermic and that higher solution temperature is required to favor the sorption process (Dahlan and Tayeh, 2014). The adsorption energy also indicates that the adsorption is a physical process. Physisorption, also called physical adsorption, is a kind of adsorption in which the electronic structure of the atom or molecule is barely perturbed upon adsorption. The adsorbates are attached to the surface through weak bonds such as van der Waals forces, hydrogen bonding, or hydrophobic interactions (Oura et al., 2003).

The BET isotherm, on the other hand, proposes a sequential multilayer adsorption model wherein each monolayer is the same with that of the Langmuir isotherm (Jain, 2006). It also assumes that the interaction on adsorbent surface is much larger than that between neighboring adsorbate molecules (Chen et al., 2017). From the BET equation, if $\mathrm{C}_{\mathrm{BET}}>1$ then the isotherm depicts a monolayer adsorption while $\mathrm{C}_{\mathrm{BET}}<1$ represents the formation of a multilayer. The calculated $\mathrm{R}^{2}$ values from the BET analysis of the adsorption of MO and BTB on lignin were 0.0023 and 0.8217 , respectively. These low values of $\mathrm{R}^{2}$ imply that the adsorption process of both dyes cannot be described by the BET model; thus, the adsorption of MO and BTB is not a sequential multilayered process.

The FH isotherm describes the degree of surface coverage characteristics of adsorbate on the adsorbent. It can also be used to determine the feasibility and spontaneous nature of an adsorption process through its equilibrium constant $\mathrm{K}_{\mathrm{FH}}$, which is used to calculate spontaneity Gibbs free energy given by the expression (Ayawei et al., 2017):

$$
\Delta G^{o}=R T \ln \left(K_{F H}\right)
$$

Equation 18

Analysis using the FH model gave $\mathrm{R}^{2}$ values of 0.9159 and 0.9966 for the adsorption of $\mathrm{MO}$ and $\mathrm{BTB}$, respectively. The calculated $\Delta \mathrm{G}^{\circ}$ for the adsorption of $\mathrm{MO}$ was $-10.04 \mathrm{~kJ} \cdot \mathrm{mol}^{-1}$ and -7.34 $\mathrm{kJ} \cdot \mathrm{mol}^{-1}$ for BTB. These negative $\Delta \mathrm{G}^{\circ}$ values suggest that the adsorption of $\mathrm{MO}$ and BTB are both spontaneous and exothermic processes (Theivarasu and Mylsamy, 2011).

The Temkin isotherm takes into account the effects of adsorbent-adsorbate interactions (Ayawei et al., 2017). By ignoring the extremely low and large value of concentrations, the model assumes that heat of adsorption of all molecules in the layer decreases linearly with coverage (Foo and Hameed, 2010). From the Temkin equation, a negative value of $b$ means that the process is exothermic and endothermic otherwise since $\mathrm{b}$ is related to the heat of adsorption (Foo and Hameed, 2010). The calculated $\mathrm{R}^{2}$ from the Temkin model was 0.9903 for the MO adsorption and 0.9829 for the adsorption of BTB. These $\mathrm{R}^{2}$ values are close to 1 , which mean that the Temkin isotherm model can be used to describe the adsorption process of the dyes on lignin. The negative $\mathrm{b}$ values obtained for MO $\left(-2240.28 \mathrm{~J} \cdot \mathrm{mol}^{-1}\right)$ and BTB $\left(-5573.75 \mathrm{~J} \cdot \mathrm{mol}^{-1}\right)$ indicate that the adsorption processes are exothermic with equilibrium rates of $0.083 \mathrm{~L} \cdot \mathrm{mg}^{-1}$ and $0.013 \mathrm{~L} \cdot \mathrm{mg}^{-1}$, respectively.

To determine which model best describes the adsorption of MO and BTB on lignin, analyses using the coefficient of determination $\left(R^{2}\right)$, sum of squared errors (SSE), sum of absolute errors (SAE), and average relative error (ARE) were employed. Values of $\mathrm{R}^{2}$ and error functions are presented in Tables 5 and 6. 
Table 5. Values of $\mathbf{R}^{2}$ and Error Analyses of Isotherm Models for the Adsorption of MO on Lignin.

\begin{tabular}{lrrrrrr}
\hline Isotherm Model & $\begin{array}{r}\mathbf{q}_{\mathbf{e}, \mathbf{e x p}} \\
\left(\mathbf{m g} \cdot \mathbf{g}^{-\mathbf{1}}\right)\end{array}$ & $\begin{array}{r}\mathbf{q}_{\mathbf{e}, \mathbf{c a l}} \\
\left(\mathbf{m g} \cdot \mathbf{g}^{-1}\right)\end{array}$ & $\mathbf{R}^{\mathbf{2}}$ & SSE & SAE & ARE (\%) \\
\hline Langmuir & & 1.92 & 0.8312 & 3.58 & 6.21 & 36.83 \\
Freundlich & & 1.29 & 0.9167 & 0.09 & 1.11 & 9.08 \\
DR & 1.23 & 1.30 & 0.8180 & 0.20 & 1.55 & 13.12 \\
BET & -- & 0.0023 & 0.35 & 1.33 & 20.34 \\
FH & & 1.29 & 0.9159 & 0.09 & 1.10 & 8.97 \\
Temkin & & 1.24 & 0.9903 & 0.01 & 0.35 & 3.52 \\
\hline
\end{tabular}

Table 6. Values of $\mathbf{R}^{2}$ and Error Analyses of Isotherm Models for the Adsorption of BTB on Lignin.

\begin{tabular}{|c|c|c|c|c|c|c|}
\hline Isotherm Model & $\begin{array}{r}q_{e, e x p} \\
\left(\mathrm{mg}^{-} \mathrm{g}^{-1}\right) \\
\end{array}$ & $\begin{array}{r}q_{\mathrm{e}, \mathrm{cal}} \\
\left(\mathrm{mg} \cdot \mathrm{g}^{-1}\right) \\
\end{array}$ & $\mathbf{R}^{2}$ & SSE & SAE & ARE (\%) \\
\hline Langmuir & & 1.56 & 0.9983 & 0.0003 & 0.03 & 0.12 \\
\hline Freundlich & & 1.57 & 0.9805 & 0.0002 & 0.02 & 0.08 \\
\hline DR & 1.57 & 1.56 & 0.9614 & 0.0003 & 0.03 & 0.12 \\
\hline BET & & 1.50 & 0.8217 & 3.2554 & 3.48 & 14.94 \\
\hline $\mathrm{FH}$ & & 1.57 & 0.9966 & 0.0002 & 0.02 & 0.08 \\
\hline Temkin & & 1.57 & 0.9829 & 0.0001 & 0.01 & 0.04 \\
\hline
\end{tabular}

The SSE, the most used error function, is the error difference between the observed value and the predicted value. However, it has a disadvantage of increasing the squared errors as the adsorbate concentration increases (Kajjumba et al., 2018), which leads to the use of SAE and ARE. The SAE provides better adjustments for higher concentrations while ARE attempts to minimize the fractional error distribution across the entire concentration range (Piccin et al., 2011). Analysis of Table 5 shows that Langmuir, BET, and DR models did not show high accuracy as indicated by their low $\mathrm{R}^{2}$ and high error values, and thus cannot be used to predict the adsorption of $\mathrm{MO}$ on lignin. On the other hand, Temkin, Freundlich, and FH have high $\mathrm{R}^{2}$ values and low error values, which means that these isotherm models can be used to describe the adsorption equilibrium. Among the three isotherm models, Temkin has the closest calculated $\mathrm{q}_{\mathrm{e}}$ value $\left(1.24 \mathrm{mg} \cdot \mathrm{g}^{-1}\right)$ to the actual (1.23 mg.g-1), the highest $\mathrm{R}^{2}$ value (0.9903), and the smallest errors in all cases (SSE $=0.01$, $\mathrm{SAE}=0.35, \mathrm{ARE}=3.52 \%$ ); hence, Temkin is considered the most useful isotherm model for describing the adsorption of MO on lignin. It can therefore be assumed that: (a) the adsorption process is spontaneous and exothermic indicated by the low b value; (b) the adsorption is characterized by a uniform distribution of binding energies (Piccin et al., 2011); and (c) there are weak interactions between the adsorbent and the adsorbate (Ayawei et al., 2017).

For BTB, it can be seen in Table 6 that the BET model had the lowest $\mathrm{R}^{2}$ and the highest errors; thus BET assumptions cannot be applied on the adsorption process. On the other hand, Langmuir isotherm has the highest $\mathrm{R}^{2}$ value; however as mentioned earlier, the obtained negative $\mathrm{R}_{\mathrm{L}}$ value also makes it an invalid model for the adsorption of BTB on lignin. The remaining isotherm models are all linear enough to describe the adsorption equilibrium but since the Temkin isotherm has the smallest error values (SSE $=0.0001, \mathrm{SAE}=0.01, \mathrm{ARE}=0.04 \%$ ), it was considered the best fit model to the adsorption process of BTB on lignin. Thus it can be assumed that the adsorption of BTB is also exothermic in nature, and that weak interactions are present between the surface of the adsorbent and the adsorbate (Ayawei et al., 2017). 
Although Temkin is the best fit model for both substrates, calculations from other models can still be used for the analysis of the adsorption process as long as the coefficient of determination of the isotherm predicts that it is linear enough (Piccin et al., 2011). Thus, Freundlich and FH are still considered valid and can still be used to describe the adsorption of MO and BTB on lignin. The Freundlich model confirms the heterogeneity of the surface of lignin (Desta, 2013). Meanwhile, the negative $\Delta G^{\circ}$ values obtained from the Flory-Huggins model proves that the adsorption processes of both $\mathrm{MO}$ and BTB on lignin are spontaneous and exothermic.

\section{CONCLUSIONS}

Lignin was isolated from rice (Oryza sativa L.) husk using alkaline method giving a $16.94 \%$ yield. Characterization of the product lignin was done using FT-IR spectroscopy. The IR spectrum obtained showed a peak at $3431.25 \mathrm{~cm}^{-1}$, which corresponds to the $\mathrm{O}-\mathrm{H}$ stretching. The large absorption area implied that the isolated alkali lignin was abundant in $\mathrm{O}-\mathrm{H}$ group. A signal at $1627.10 \mathrm{~cm}^{-1}$ can be assigned to the presence of $\mathrm{C}=\mathrm{C}$ in conjugated alkenes. A characteristic absorption peak of lignin was found at $1508.31 \mathrm{~cm}^{-1}$ due to the skeleton stretching vibrations of aromatic ring. A peak was also observed at $1160.25 \mathrm{~cm}^{-1}$ due to the $\mathrm{C}-0$ stretching in tertiary alcohol while the signal at $1042.13 \mathrm{~cm}^{-1}$ can be attributed to deformation vibrations of $\mathrm{C}-\mathrm{H}$ bonds in guaiacyl rings. Lastly, the peaks at 860.36 and $787.5 \mathrm{~cm}^{-1}$ are due to deformation vibrations of $\mathrm{C}-\mathrm{H}$ (out of plane) bonds associated to aromatic rings.

After characterization, the extracted alkali-lignin was used as an adsorbent for MO and BTB. For the adsorption of MO, the adsorption rate initially increased with an increase in contact time and gradually led to equilibrium, which was achieved at around 150 minutes with an experimental $\mathrm{q}_{\mathrm{e}}$ of $1.23 \mathrm{mg} \cdot \mathrm{g}^{-1}$ and a removal rate of $61.4 \%$ at equilibrium. On the other hand, BTB readily adsorbed onto lignin and reached equilibrium at a contact time of 150 minutes with an experimental $\mathrm{q}_{\mathrm{e}}$ of $1.57 \mathrm{mg} \cdot \mathrm{g}-1$ and a $78.3 \%$ removal rate at equilibrium.

The rate of reaction of each adsorption process was determined using PFO and PSO kinetic models. The kinetic model that best fits the experimental data for both adsorption processes was determined by calculating the coefficient of determination, $\mathrm{R}^{2}$, and the standard deviation, $\Delta \mathrm{q}$. Kinetic analysis showed that both the adsorption of MO and BTB onto lignin followed a PSO rate of reaction at $6.84 \times 10^{-3} \mathrm{~g} \cdot \mathrm{mg}^{-1} \cdot \mathrm{min}^{-1}$ and $0.69 \mathrm{~g} \cdot \mathrm{mg}^{-1} \cdot \mathrm{min}^{-1}$, respectively.

Analysis using adsorption isotherms was also performed using Langmuir, Freundlich, DubininRadushkevich, Brunauer-Emmett-Teller, Flory-Huggins, and Temkin isotherm models. The best fit model for the adsorption data of methyl orange and bromothymol blue was determined using the coefficient of determination, $\mathrm{R}^{2}$, sum of squared errors (SAE), sum of absolute errors (SAE), and absolute relative error (ARE).

For the analysis of the adsorption of MO on lignin, the Temkin isotherm was found to be the most appropriate model to describe the adsorption process as indicated by its highest $\mathrm{R}^{2}$ value of 0.9903 , and smallest error values (SSE $=0.01, \mathrm{SAE}=0.35$, and ARE $=3.52 \%$ ). The calculated heat of sorption was $-2240.28 \mathrm{~J} \cdot \mathrm{mol}^{-1}$, which implies that the adsorption process is exothermic with an equilibrium rate of $0.083 \mathrm{~L} \cdot \mathrm{mg}^{-1}$. The calculated $\mathrm{q}_{\mathrm{e}}$ was $1.24 \mathrm{mg} \cdot \mathrm{g}^{-1}$, which was also the closest value to the experimental $\mathrm{q}_{\mathrm{e}}$ of $1.23 \mathrm{mg} \cdot \mathrm{g}^{-1}$.

The determination of the best-fit model also showed that the Temkin isotherm was the appropriate model to describe the adsorptive removal of BTB. The calculated values of $\mathrm{R}^{2}$, SSE, SAE, and ARE are $0.9829,0.0001,0.01$, and $0.04 \%$, respectively. The calculated heat of sorption was $-5573.75 \mathrm{~J} \cdot \mathrm{mol}^{-1}$; thus, the reaction is exothermic. The equilibrium rate constant was found to be $0.013 \mathrm{~L} \cdot \mathrm{mg}^{-1}$ with a calculated $\mathrm{q}_{\mathrm{e}}$ equal to the experimental $\mathrm{q}_{\mathrm{e}}$ of $1.57 \mathrm{mg} \cdot \mathrm{g}^{-1}$. 
For both adsorption processes, it can be assumed that there are weak interactions between the adsorbate and the adsorbent's surface. Temkin model also assumes that as the coverage increases, the heat of adsorption of all molecules in the layer decreases.

It is recommended that the optimization of other parameters such as temperature and pH before performing batch experiments for dye adsorption be considered to increase adsorption capacity. It is also recommended that an SEM analysis of the adsorbent-adsorbate interactions be observed to be able to further explain the nature of their interaction.

\section{REFERENCES}

Agarwal S, Sadegh H, Monajjemi M, Hamdy AS, Ali GAM, Memar AOH, et al. Efficient removal of toxic bromothymol blue and methylene blue from wastewater by polyvinyl alcohol. J Mol Liq. 2016 June; 218:191-197. https://doi.org/10.1016/j.molliq.2016.02.060

Agarwal A, Rana M, Park JH. Advancement in technologies for the depolymerization of lignin. Fuel Process Technol. 2018 December; 181:115-132. https://doi.org/10.1016/j.fuproc.2018.09.017

Aliabadi HM, Saberikhah E, Pirbazari AE, Khakpour R, Alipour H. Triethoxysilylpropylamine modified alkali treated wheat straw: an efficient asdorbent for methyl orange adsorption. Cellul Chem Technol. 2018; 52(1-2): 129-140. https://www.cellulosechemtechnol.ro/pdf/CCT12(2018)/p.129-140.pdf

Ayawei N, Ebelegi AN, Wankasi D. Modelling and interpretation of adorption isotherms. J Chem. 2017 September; 2017:3039817. https://doi.org/10.1155/2017/3039817

Bharathi KS, Ramesh ST. Removal of dyes using agricultural waste as low-cost adsorbents: a review. Appl Water Sci. 2013 July; 3:773-790. https://doi.org/10.1007/s13201-013-0117-y

Beduk T. Lignin as an antistatic additive for common polymers [thesis]. [Turkey]: Graduate School of Engineering and Science of Bilkent University; 2018. http://repository.bilkent.edu.tr/bitstream/handle/11693/35751/10178104\%20TUTKU\%20B EDUK.pdf?sequence=1\&isAllowed=y

Chen Q, Tian Y, Peng L, Yan C, Pang Y, Zheng L, et al. Study on shale adsorption equation based on monolayer adsorption, multilayer adsorption, and capillary condensation. J Chem. 2017 October; 2017:1496463. https://doi.org/10.1155/2017/1496463

Conti JP. Optimization of alkali concentration, time, and temperature in the alkali lignin extraction from pineapple (Ananas comosus (L.) Merr.) husks and rice (Oryza sativa L.) husks [thesis]. [Philippines]: University of the Philippines Los Baños; 2019.

Dahlan I, Tayeh SMO. Removal of colour from synthetic dye wastewater using adsorbent prepared from psyllium husk. In: Aziz HA, Mojiri A, editors. Wastewater engineering: advanced wastewater treatment systems. Malaysia: IJSR Publications; 2014. Chapter 2, Wastewater treatment by physical-chemical technologies; p. 15-30. https://www.researchgate.net/profile/AminMojiri/publication/320083389 Wastewater Engineering Advanced Wastewater Treatment Sy stems/links/59ccfe3ea6fdccf8cf34b817/Wastewater-Engineering-Advanced-WastewaterTreatment-Systems.pdf

Desta MB. Batch sorption experiments: Langmuir and Freundlich isotherm studies for the adsorption of textile metal ions onto teff straw (Eragrostis tef) agricultural waste. J Thermodyn. 2013 September; 2013:375830. https://doi.org/10.1155/2013/375830 
Foo KY, Hameed BH. Insights into modeling of adsorption isotherm systems. Chem Eng J. 2010 January; 156(1):2-10. https://doi.org/10.1016/j.cej.2009.09.013

Gong R, Ye J, Dai W, Yan X, Hu J, Hu X, et al. Adsorptive removal of methyl orange and methylene blue from aqueous solution with finger-citron-residue-based activated carbon. Ind Eng Chem Res. 2013 September; 52(39):14297-14303. https://doi.org/10.1021/ie402138w

Han W, Luo L, Zhang S. Adsorption of bisphenol A on lignin: effects of solution chemistry. Int J Environ Sci Technol. 2012 April; 9: 543-548. https://doi.org/10.1007/s13762-012-0067-1

Hu Q, Zhang Z. Application of dubinin-radushkevich isotherm model at the solid/solution surface: a theoretical analysis. J Mol Liq. 2019 March; 277:646-648. https://doi.org/10.1016/j.molliq.2019.01.005

Hua W, Liu C, Wu SB, Li XH. Analysis of structural units and their influence on thermal degradation of alkali lignins. BioRes. 2016 January; $11 \quad$ (1), 1959-1970. https://doi.org/10.15376/biores.11.1.1959-1970

Jain, A. Lignin as an adsorbent for the removal of dyes from waste water [dissertation]. [Roorkee]: Indian Institute of Technology Roorkee, Saharanpur Campus; 2016. http://shodhbhagirathi.iitr.ac.in:8081/jspui/bitstream/123456789/12780/3/dUPLICATE.pdf

Kajjumba GW, Emik S, Öngen A, Özcan HK, Aydin S. Modelling of adsorption kinetic processes errors, theory and application. In: Sorption. [Internet]. IntechOpen Limited; 2018 November. p. 1-19. Available from: https://www.intechopen.com/books/advanced-sorption-processapplications/modelling-of-adsorption-kinetic-processes-errors-theory-and-application

Kucharska K, Rybarczyk P, Holowacz I, Lukajtis R, Glinka M, Kaminski M. Pretreatment of lignocellulosic materials as substrates for fermentation processes. Molecules. 2018 November; 23(11):2937. https://doi.org/10.3390/molecules23112937

Liu MH, Huang JH. Removal and recovery of cationic dyes from aqueous solutions using spherical sulfonic lignin adsorbent. J Appl Polym Sci. 2006 May; 101(4):2284-2291. https://doi.org/10.1002/app.23671

Ma J, Yu F, Zhou L, Jin L, Yang M, Luan J, et al. Enhanced adsorptive removal of methyl orange and methylene blue from aqueous solution by alkali-activated multiwalled carbon nanotubes. ACS Appl Mater Interfaces. 2012 October; 4 (11): 5749-5760. https://doi.org/10.1021/am301053m

Mahmoudi K, Hamdi N, Kriaa A, Srasra E. Adsorption of methyl orange using activated carbon prepared from lignin by $\mathrm{ZnCl}_{2}$ treatment. Russ J Phys Chem. 2012 August; 86(8):1294-1300. https://doi.org/10.1134/S0036024412060180

Moussout H, Ahlafi H, Aazza M, Maghat H. Critical of linear and nonlinear equations of pseudofirst order and pseudo-second order kinetic models. Karbala Int J Modern Sci. 2018 June; 4(2): 244-254. https://doi.org/10.1016/i.kijoms.2018.04.001

Nair,V, Panigrahy A, Vinu R. Development of novel chitosan-lignin composites for adsorption of dyes and metal ions from wastewater. Chem Eng J. 2014 October; 254: 491-502. https://doi.org/10.1016/j.cej.2014.05.045

Nsami JN, Mbadcam JK. The adsorption efficiency of chemically prepared activated carbon from cola nut shells by ZnCl2 on methylene blue. J Chem. 2013 June; 1-7. DOI: 10.1155/2013/469170. 
Oura K, Lifshits VG, Saranin AA, Zotov AV, Katayama M. Surface science, an introduction. New York: Springer-Verlag Berlin Heidelberg; 2003.

Piccin JS, Dotto GL, Pinto LAA. Adsorption isotherms and thermochemical data of FD\&C RED N ${ }^{\circ}$ 40 binding by chitosan. Braz J Chem Eng. 2011 April; 28 (2): 295-304. https://doi.org/10.1590/S0104-66322011000200014

Robati, D. Pseudo-second-order kinetic equations for modeling adsorption systems for removal of lead ions using multi-walled carbon nanotube. J Nanostructure Chem. 2013 July; 3:55. https://doi.org/10.1186/2193-8865-3-55

Sigma-Aldrich. IR spectrum table and chart [Internet]. [date unknown] - [cited $11 \mathrm{March} 2021$ ]. Available from: https://www.sigmaaldrich.com/technical-documents/articles/biology/irspectrum-table.html

Skulcova A, Majová V, Kohutova M, Grosik M, Sima J, Jablonsky M. UV/vis spectrometry as a quantification tool for lignin solubilized in deep eutectic solvents. BioRes. 2017 July; 12(3), 67136722. https://doi.org/10.15376/biores.12.3.6713-6722

Subbaiah MV, Kim DS. Adsorption of methyl orange from aqueous solution by aminated pumpkin seed powder: kinetics, isotherms, and thermodynamic studies. Ecotoxicol Environ Saf. 2016 June; 128, 109-117. https://doi.org/10.1016/i.ecoenv.2016.02.016

Theivarasu C, Mylsamy S. Removal of malachite green from aqueous solution by activated carbon developed from cocoa (Theobroma cacao) shell - a kinetic and equilibrium studies. J Chem. 2011 December; 8:714808. https://doi.org/10.1155/2011/714808

Tumolva TP, Enguero DS, Laus TJC, Requejo BA. Green composites using lignocellulosic waste and cellulosic fibers from corn husks. 2016 3rd International Conference on Chemical and Food Engineering; 2016 April 8-9; Tokyo, Japan. Japan: MATEC Web of Conferences; 2016 June; 62:01003. https://doi.org/10.1051/matecconf/20166201003

Wang X, Jiang C, Hou B, Wang Y, Hao C, Wu J. Carbon composite lignin-based adsorbents for the adsorption of dyes. Chemosphere. 2018 Sept; 206:587-596. https://doi.org/10.1016/i.chemosphere.2018.04.183

Zhang S, Wang Z, Zhang Y, Pan H, Tao L. Adsorption of methylene blue on organosolv lignin from rice straw. Procedia Environ Sci. 2016 Jan; 31:3-11. https://doi.org/10.1016/j.proenv.2016.02.001

Zhou X. Correction to the calculation of Polanyi potential from Dubinnin-Rudushkevich equation. J Hazard Mater. 2020 February; 384: 121101. https://doi.org/10.1016/i.jhazmat.2019.121101 